\title{
River Ganga: Policy Interventions
}

\author{
Chakresh Kumar Jain ${ }^{1}$ and Surya Singh ${ }^{2 *}$ \\ ${ }^{1}$ Centre for Science and Environmental Research, Roorkee-247 667, India \\ ${ }^{2}$ National Institute of Hydrology, Roorkee-247 667, India \\ *Corresponding author: Surya Singh, Centre for Science and Environmental Research, Roorkee-247 667, India; Email: suryasingh.er@gmail.com
}

Received: May 22, 2021; Accepted: May 30, 2021; Published: September 01, 2021

\begin{abstract}
Failure of various Ganga cleaning programmes in past 3 decades forced the Indian Government to launch yet another ambitious plan in 2015, named as "Namami Gange". Apart from inclusion of few new initiatives, this plan is the repetition of previous plans in terms of approach, management, and overall agenda. Ganga, the national river of India, which has been globally recognized for decomposing organic wastes at the rate 15-25 times faster than any other river [1], is now one of the most polluted rivers of the world [2]. It indicates that there have been some untouched and/or neglected aspects in policy formulation, and most important, in understanding the peculiarity of this river.
\end{abstract}

Keywords: Namami Gange; Policy; Pollution; River Ganga

\section{Issues of Concern and Political Apathy}

More than 2,900 million liters of sewage [3] and 700 million liters of industrial effluents [4] join the river on daily basis. 194 major drains along the river stretch also discharge approximately 9,300 million liters of waste per day [5]. In addition, there are thousands of villages along the $2,525 \mathrm{~km}$ of the river course, most of which are characterized by lack of hygiene and sanitation facilities, resulting in discharge of untreated waste. Solid waste, including plastics, also makes its way into the river [6]. Floating dead bodies, animal carcasses, mass bathing, and other ritualistic practices also contribute their significant share. To assimilate such a huge amount of waste, river does not have sufficient ecological flow owing to various hydropower stations, irrigation canals, and water abstraction for drinking / industrial / commercial purposes. Reduction in southwest monsoonal rainfall over the Ganga basin is also a reality [7]. All this has led to the situation where Ganga can no longer be able to provide its ecosystem services to the full extent. In past 30 years, numerous efforts took place at the government and institutional levels to purify the Ganga; but the complex web of centre-state relations, bureaucratic hurdles, and corruption have resulted only in the wastage of huge amount of public money with minimal results. Notably, in the starting phase of action plans, $100 \%$ funds were given by the central government. From 1993, 50:50 sharing of funds was adopted by states and centre, which later changed to 30:70 i.e. (involved) states were required to contribute $30 \%$ of capital, and operation and maintenance cost; while the central government contributed the rest $70 \%$. This financial arrangement also proved to be unsustainable for the states in the long term and eventually, central government contributed $100 \%$ towards the funds as well as planning. In all these scenarios, local municipalities, which are the foundation stone for the implementation and success of any project, were left out of the decision making. These institutions have never been authorized to fund the operation and maintenance of the facilities through local resources, which ultimately resulted in the collapse of expensive infrastructure. Lack of political will, lacunae in enforcement of environmental laws, and unplanned developmental activities have further acted as catalysts in the malfunctioning of the entire system. Technological challenges have also played a significant role in the overall mis-management. Previous policies have mainly focused on the establishment of sewage treatment plants in order to arrest pollution in the river. Huge investments were made for the advanced energy intensive technologies; however, the issue which was forgotten was the local conditions to operate the facilities. Analysis reveals that at the planning stage, there was always existed massive gap between the vision and the on-ground implementation. Approach has always been to use the world class technologies, but constant inflow of funds to meet operation and maintenance cost, continuous power supply to run the facilities, skilled labor, and effective and responsible operation could not be ensured. It led to the under-performance and in some cases, shut-down of the wastewater treatment facilities. Nevertheless, in many of the cities where STPs were established, there is still no sewerage system for conveying city sewage up to the STPs, thus turning the whole purpose futile. On the other hand, open defecation practice is still prevalent in many rural and urban areas. Although government has created millions of toilets under its 'Clean India Mission', but their regular usage is doubtful because, in a country like India where 97 million people are surviving without any access to improved sources of drinking water [8], using water for sanitation is deemed as wastage. In such a situation it is not surprising that diarrhea alone is the third leading cause of childhood mortality in India [9]. What was wrong here was the lack of understanding to maintain corelation between the sanitation and water availability. Development of water-less toilets would have been an attractive option to motivate people for their use. 


\section{Policy Recommendations}

Till date, Ganga clean-up programmes in India have been designed on the lines of remediation plans of foreign rivers (e.g. Thames River, Rhine River etc.) forgetting the fact that Ganga is much different from those rivers. Ganga is a South Asian river which holds attributes of geographical, geological, social, and cultural uniqueness and therefore, management efforts are also needed to be exclusive.

\section{Figuring out the Full Picture}

It is known that $\sim 70-80 \%$ pollution load in this river comes from the municipal sewage. However, rest of the pollution can be attributed to various industrial effluents and other important sources [10]. Incomplete estimation of the pollution sources and focus on only single issue has been one of the major reasons for the failure of previous policies. Solid waste dumping into the river has not been given much attention. Huge gap lies between the solid waste generation and available treatment capacity (Figure 1). Non-point source pollution is also very significant but it has been altogether neglected in earlier approaches. Agricultural pollution is the most significant nonpoint source, considering the fact that India is an agrarian country. Cultivation area is decreasing every year and therefore in order to enhance production, huge quantities of chemical fertilizers and pesticides are often applied blindly (Figure 2). Runoff from more than 6 million tons of fertilizers and 9000 tons of pesticides (including DDT) are added annually into the Ganga [11]. These agro-chemicals slowly accumulate in the river-bed sediments which often act as sink for various chemical species and heavy metals [12]. Hence, there is need to focus on such farming systems that will reduce agricultural pollution while maintaining farm income. More emphasis needs to be given for adoption of organic farming practices. Rural landscape management is also an impressive programme which ensures the conservation and management of ecosystems by handling non-point source pollution $[13,14]$. Government also needs to play an effective role for the formulation and implementation of laws and regulations in order to control pesticide/fertilizer pollution.

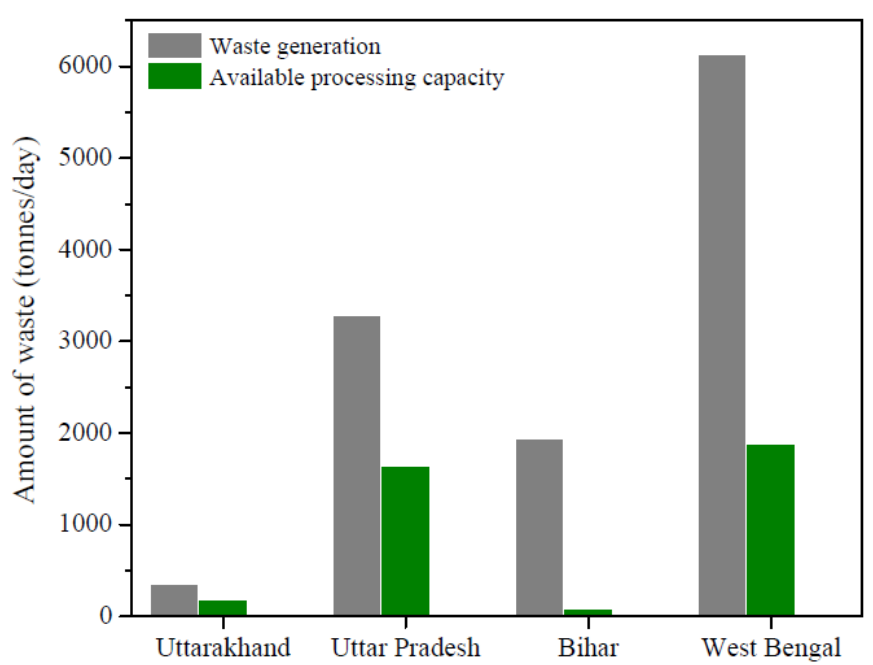

Figure 1: Solid waste generation and available treatment capacity in the Ganga states (Data source: Lok Sabha, India).
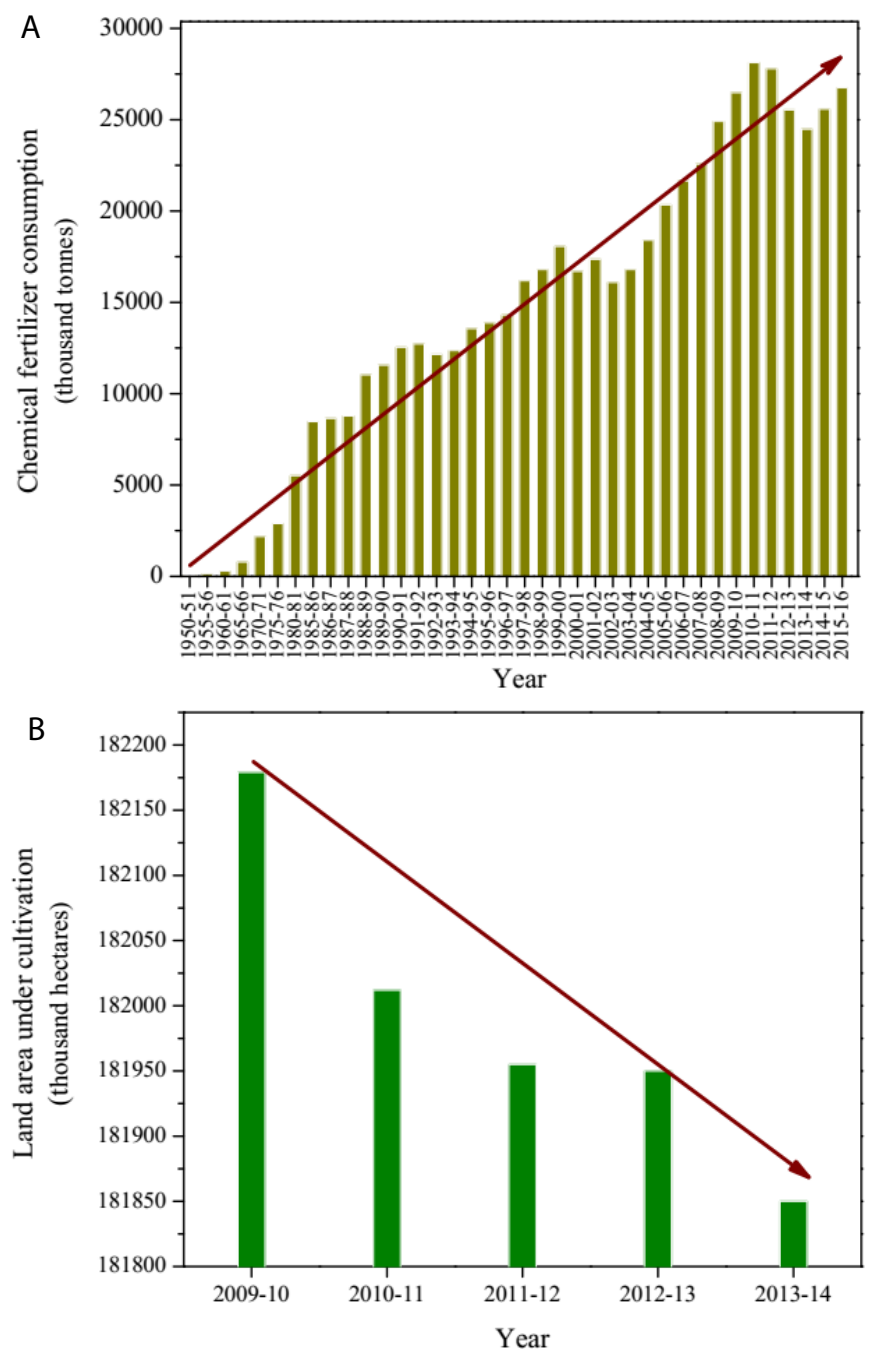

Figure 2: Increasing usage of chemical fertilizers (a) and decreasing land area under cultivation in India (b) depicts that significant amount of un-utilized chemicals might be contributing to non-point source pollution (Data source: Agricultural statistics at a glance, India).

Previous policies also lacked initiatives for the estimation of river sediments. Sediments analysis in river bed is highly desirable as Ganga is supposed to carry approximately 403-660 $\times 10$ [6] tonnes of sediments annually [15], of which $88 \%$ of the annual sediment load is restricted only during monsoons [16]. Further, high density of dams and barrages in upper reaches of Ganga trap the sediments and thus hinder their smooth flow resulting in the impact on overall ecological characteristics and water quality of the river. It is therefore advised that sediment load analysis and management should be made an inclusive part of the Ganga rejuvenation policies.

\section{Coordinated Efforts}

In India, there are many governing bodies which work in an uncoordinated manner. There is Ministry of Jal Shakti, which is an apex body for formulation and administration of rules and regulations for development and regulation of water resources in India. Ministry of Environment, Forest, and Climate Change deals with conserving natural resources including rivers, along with the prevention and abatement of pollution. And, Ministry of Rural Development aims 
to provide urban amenities in rural areas. Apart from these, there are numerous other agencies, authorities, and pollution control boards at both the centre and state levels. Un-coordinated efforts among these bodies often lead to delays/non-implementation of the projects, mismanagement of funds, corruption, duplicacies, conflicts, and finally, the failure of initiatives. To minimize such things, a tremendous upheaval is required in the existing system through a well-planned set-up with overall aim to curb pollution. Various non-governmental organizations, private enterprises, and public should also be involved. Proper documentation and information dissemination also needs to be maintained in order to keep the system transparent and accountable.

\section{Embracing the Change}

Change in mindset and attitude plays a big role. As of now, there are numerous rules and regulations in the country, but those are hardly practiced. Upon violation, the common tendency among the citizens / industries is to bribe the officials and get away from the cumbersome process of litigation. Therefore, changes in the law-making and enforcement are highly desirable. Further, it is also necessary to carry out extensive ground level studies to estimate the performance of any advanced water treatment technology in Indian scenario before its implementation. Unsustainable development of numerous projects in the Ganga basin shall only paralyse the already suffering river [17] and therefore, impact/risk assessment methods should not be made lenient in order to promote development. Also, industries can be leveraged with the additional responsibility of treating and re-using their effluents to the maximum extent possible. Ganga rejuvenation is the responsibility of each and every citizen and hence, at the individual level there is immense need to bring changes in values, attitude, and behavior towards water. Education and awareness are extremely important for this. Importance of clean and uncontaminated water resources needs to be understood by everyone. Minimization of waste generation and attitude to re-use the things is highly recommended in this regard. Reducing the pressure on the ecosystem services which a river can provide might further help in the overall improvement in the health of the river.

\section{Conclusion}

There is necessity to understand the loopholes in the existing system and willingness to overcome. Comprehensive assessment of the policies is required before and after implementation and authorities need to be made accountable for their actions. Although, some initiatives are being taken by the Indian government but those are not enough. Effective policy framework along with the mass awareness is highly solicited in Indian context.

\section{Declaration of Interest Statement}

Authors declare that there are no conflicts of interest.

\section{Funding}

This research did not receive any specific grant from funding agencies in the public, commercial, or not-for-profit sectors.

\section{References}

1. Bhargava DS (1981) Ganga, the most self purifying river. In: Proceedings of International Symposium on Water Resources Conservation, Pollution and Abatement, Roorkee, India.

2. Rai B (2013) Pollution and conservation of Ganga River in modern India. Int J Sci Res Pub 3: 1-4.

3. http://www.hindustantimes.com/delhi-news/ganga-receives-2-900-million-ltrsof-sewage-daily/story-SApumDD2zFUTUtb3AtpC9K.html (accessed 12 October, 2017).

4. http://www.dnaindia.com/india/report-700-mn-litres-of-waste-dumped-each-daycpcb-2384790 (accessed 12 October, 2017)

5. Central Pollution Control Board (CPCB) Report, Identified and priority drains in phase/segment wise, Personal Communication, 2017.

6. Lebreton LCM, Zwet JV, Damsteeg JW, Slat B, Andrady A, et al. (2017) River plastic emissions to the world's oceans. Nat Commun 8: 1-10.

7. Paul S, Ghosh S, Oglesby R, Pathak A, Chandrasekharan A, et al. (2016) Weakening of Indian summer monsoon rainfall due to changes in land use land cover. Sci Rep 6: $1-10$.

8. http://www.who.int/water_sanitation_health/monitoring/jmp2012/fast_facts/en/ (accessed 20 August, 2017).

9. Lakshminarayanan S, Jayalakshmy R (2015) Diarrheal diseases among children in India: Current scenario and future perspectives. J Nat Sci Biol Med 6: 24-28. [crossref]

10. Dwivedi S, Mishra S, Tripathi RD (2018) Ganga water pollution: A potential health threat to inhabitants of Ganga basin. Environ Int 117: 327-338. [crossref]

11. UNDP Human Development Report (1998) Oxford University Press, NewYork, pg: 69.

12. Pandey J, Singh R (2017) Heavy metals in sediments of Ganga River: up- and downstream urban influences. Appl Water Sci 7: 1669-1678.

13. Idda L, Madau FA, Orru E, Pulina P, Sini MP (2005) Efficacy of European policies on rural landscape: the case study of Sardinia (Italy), $X I^{\text {th }}$ Congress of the European Association of Agricultural Economists, , Copenhagen, Denmark.

14. Estrada-Carmona N, Hart AK, DeClerck FAJ, Harvey CA, Milder JC (2014) Integrated landscape management for agriculture, rural livelihoods, and ecosystem conservation: An assessment of experience from Latin America and the Carribean. Landscape Urban Plan 129: 1-11.

15. Subramanian V, Ramanathan AL (1996) "Nature of sediment load in the GangesBrahmaputra River systems in India" in Sea-level rise and coastal subsidence, Coastal Systems and Continental Margins. Springer, Netherland 2: pg: 151-168.

16. Subramanian V (1996) The sediment load of Indian rivers - an update, Erosion and sediment yield: Global and regional perspectives, Proceedings of the Exeter Symposium. IAHS Publication no. 236.

17. Pandit MK, Grumbine RE (2012) Potential effects of ongoing and proposed hydropower development on terrestrial biological diversity in the Indian Himalaya. Conser Bio 26: 1061-1071. [crossref]

\section{Citation:}

Jain CK, Singh S (2021) River Ganga: Policy Interventions. Geol Earth Mar Sci Volume 3(2): 1-3. 